\title{
Hot Extrusion Effect on the Microstructure and Mechanical Properties of a Mg-Y-Nd-Zr Alloy
}

\author{
L. Y. Sheng, ${ }^{a, 1}$ B. N. Du, ${ }^{a}$ B. J. Wang, ${ }^{a}$ D. K. Xu, ${ }^{b}$ C. Lai, ${ }^{a}$ Y. Gao, ${ }^{c}$ and T. F. Xi \\ ${ }^{a}$ Shenzhen Institute, Peking University, Shenzhen, China \\ ${ }^{\mathrm{b}}$ Key Laboratory of Nuclear Materials and Safety Assessment, Institute of Metal Research, Chinese \\ Academy of Sciences, Shenyang, China \\ c Department of Stomatology, Longgang District Central Hospital, Affiliated to Zunyi Medical \\ College, Shenzhen, Guangdong, China \\ ${ }^{1}$ lysheng@yeah.net
}

A Mg-Zn-Y-Nd alloy was prepared by casting and hot extrusion. The microstructure and mechanical properties of OM, SEM, XRD, TEM, and tensile tests were investigated with casting and hot extruded alloys. The results demonstrate that in a casting $\mathrm{Mg}-\mathrm{Y}-\mathrm{Nd}-\mathrm{Zr}$ alloy, the $\alpha-M g$ matrix is separated into the cell structure by a discontinuously distributed coarse $M_{24} Y_{5} / \alpha-M g$ entectic structure and fine $\mathrm{Mg}_{12} \mathrm{Nd}$ particles. TEM analysis shows that the $\mathrm{Mg}_{12} \mathrm{Nd}$ and $\mathrm{Mg}_{24} Y_{5}$ phases have the orientation of $[001]_{\mathrm{Mg}_{12} \mathrm{Nd}} / /[02 \overline{2} 1]_{\alpha-\mathrm{Mg}}$, and $[111]_{\mathrm{Mg}_{24} \mathrm{Y}_{5}} / /[0001]_{\alpha-\mathrm{Mg}}$ and $(10 \overline{1})_{\mathrm{Mg}_{24} \mathrm{Y}_{5}} / /(10 \overline{10})_{\alpha-\mathrm{Mg}}$, respectively. The hot extrusion separates the $\mathrm{Mg}_{24} \mathrm{Y}_{5} / \alpha-M g$ eutectic structure into fragments and aligns fragmentary $\mathrm{Mg}_{24} Y_{5}$ particles along the extrusion direction. The interaction of hot extrusion and strengthening particles refines the $\alpha-M g$ matrix greatly. Moreover, large strains result in the stacking faults of the matrix. As compared to the casting alloy, the hot-extruded one exhibits high yield strength, ultimate tensile strength, and elongation, which should be ascribed to the grain fineness, optimum distribution of strengthening particles and multiple substructures.

Keywords: $\mathrm{Mg}-\mathrm{Y}-\mathrm{Nd}-\mathrm{Zr}$ alloy, hot extrusion, mechanical properties, $\mathrm{TEM}$, microstructure.

Introduction. Magnesium $(\mathrm{Mg})$ alloys have attracted much attention as light-weight structural materials because of their low density, good damping properties, high specific strength and ease of recycling, which can be applied in many fields, including implants, hand tools, sports equipment, automobiles, aerospace applications and electronic equipment [1-4]. Moreover, recent research exhibited that the clinic trial of coronary stents made from rare earth-doped $\mathrm{Mg}$ alloy exhibited a good therapeutic effect without thrombosis, which demonstrated good application prospects of Mg-based implant [5]. However, the Mg matrix possessed the hexagonal close-packed (HCP) crystal structure, which limited the number of initiation slip systems during deformation at relative low temperature and resulted in its poor deformability [6]. However, poor ductility and low strength of $\mathrm{Mg}$ alloy hinder its wide application. To mitigate these shortcomings of $\mathrm{Mg}$ alloy, many methods had been applied [7-9]. Alloying and thermal processing are assumed as efficient methods to improve mechanical properties of $\mathrm{Mg}$ alloy at high and room temperatures.

Recently, many studies were carried out on the rare earth-modified $\mathrm{Mg}$ alloy, including $\mathrm{Y}, \mathrm{Nd}, \mathrm{Gd}$, etc. Among them, the $\mathrm{Y}$ element was considered as the most suitable one to strengthen $\mathrm{Mg}$ alloy [10-12], due to its smaller atomic mass than other rare earth elements. Cheng et al. [13] studied the minor Y-doped Mg alloy and revealed that a minor addition of $\mathrm{Y}$ increases the impact toughness by changing the deformation mode from twinning to dislocation slip. Kula et al. [14] investigated the deformation behavior of the $\mathrm{Mg}-\mathrm{Y}$ alloy and reported that the addition of $\mathrm{Y}$ can change the fracture mode by improving the dislocation motion. Moreover, Li studied the $\mathrm{Y}$ and $\mathrm{Zn}$-doped $\mathrm{Mg}$ alloy and proved that the formed long period stacking ordered structure was beneficial to the strength [15]. Li et 
al. [16] investigated the $\mathrm{Nd}$-doped $\mathrm{Mg}-\mathrm{Zn}-\mathrm{Zr}$ alloy and showed that $\mathrm{Nd}$ could enhance the alloy strength. Moreover, the precipitation by the aging treatment improved the alloy strength. However, the improvement by $\mathrm{Y}$ or $\mathrm{Nd}$ is limited, so other researchers added multicomponent rare earth elements to $\mathrm{Mg}$ alloy. The recent investigation on the $\mathrm{Y}$ and Nd-modified alloy revealed that the formation of $\beta_{1}$ phase was beneficial to the strength [17]. Though the addition of $\mathrm{Nd}$ and $\mathrm{Y}$ improved the strength of the $\mathrm{Mg}$ alloy, but their low solid solubility in the Mg matrix promoted their segregation along the grain boundary during the solidification, which was detrimental to the ductility. Therefore, the treatment and thermal processing (extrusion, forging and rolling) were applied to optimize the microstructure of the rare earth-modified $\mathrm{Mg}$ alloy to improve its mechanical properties. Zhao et al. [18] applied hot-extruded and equal-channel angular pressing to prepare $\mathrm{Mg}-\mathrm{Nd}-\mathrm{Zn}-\mathrm{Zr}$ alloy with an ultrafine microstructure and improved the strength and ductility. Liu et al. [19] produced WE54 alloy by large-scale plastic deformation and revealed that the increased deformation degree promoted the microstructure refinement and improved the high-temperature performance. Although severe thermal processing could increase mechanical properties of $\mathrm{Mg}$ alloy by great microstructure refinement, its application was limited due to its size limitation. In the tube-processing, the hot extrusion process is still the main method. Based on the application of $\mathrm{Mg}$ alloy in biomedical implants, the conventional extrusion processing is still required. Therefore, in the present research, the $\mathrm{Mg}-\mathrm{Y}-\mathrm{Nd}-\mathrm{Zr}$ alloy was prepared by casting and subsequent hot extrusion at relatively low temperatures. The microstructure evolution and mechanical properties of casting and hot-extruded alloys were investigated simultaneously.

1. Experimental Procedures. Pure Mg (>99.95\%), Mg-25Y, Mg-25Nd, Mg-30Zr (wt.\%) master alloys were used as raw materials to fabricate the $\mathrm{Mg}-\mathrm{Y}-\mathrm{Nd}-\mathrm{Zr}$ alloy with a chemical composition of $\mathrm{Mg}-4.6 \mathrm{Y}-3.8 \mathrm{Nd}-0.45 \mathrm{Zr}$ (wt.\%). During the metallurgical process, raw materials were melted in an electric resistance furnace at about $750^{\circ} \mathrm{C}$ under the protection of $\mathrm{CO}_{2}$ and $\mathrm{SF}_{6}$ with the ratio of 99:1. After then the melted alloy was poured into the mild steel crucible to get casting rods $(\varnothing 150 \times 400 \mathrm{~mm})$ and the crucible was preheated to $240-320^{\circ} \mathrm{C}$. Some casting rods were studied in the casting state, the others were heat-treated at $440^{\circ} \mathrm{C}$ for $4 \mathrm{~h}$ and, subsequently, hot extruded at $400^{\circ} \mathrm{C}$ with an extrusion ratio of $8: 1$.

Specimens for tensile testing and microstructure observation were cut from casting and hot-extruded rods, respectively. Axiovert 200 MAT optical microscope (OM), Phenom ${ }^{\mathrm{TM}}$ Pro and S-3400 scanning electron microscopes (SEMs) were used to carry out microstructure observation. Specimens for SEM and OM observation were grinded, polished and chemically etched with a solution of $5 \%$ nitric acid and $90 \%$ alcohol. The resultant phases in the $\mathrm{Mg}-\mathrm{Y}-\mathrm{Nd}-\mathrm{Zr}$ alloy were studied by X-ray diffraction (XRD) with a $\mathrm{Cu}$ radiation at $40 \mathrm{kV}$ and $40 \mathrm{~mA}$. The observation of precipitates and crystal defects were performed using a JEOL-2010 transmission electron microscope (TEM) at an acceleration voltage of $200 \mathrm{kV}$. The slices with $0.4 \mathrm{~mm}$ thickness were cut from the casting and hot extruded alloys to prepare TEM specimens. The slice was polished to $30 \mu \mathrm{m}$ and shaped into $\varnothing 3 \mathrm{~mm}$ followed by twin-jet electropolishing in a solution of $90 \%$ alcohol and $10 \%$ perchloric acid at $-20^{\circ} \mathrm{C}$. During the twin-jet electropolishing, the twin-jet current is maintained at $40 \mathrm{~mA}$. The energy dispersive spectroscope (EDS) attached in TEM and SEM was used to analyze the chemical compositions of constitute phases. The tensile specimens had the gauge length of $8 \mathrm{~mm}$, thickness of $1.5 \mathrm{~mm}$, and width of $2 \mathrm{~mm}$. For the hot-extruded alloy, the tensile axis was parallel to the extrusion direction. The SANSCMT5105 tensile testing machine was used to perform tensile tests with an initial strain rate of $1 \cdot 10^{-3} \mathrm{~s}^{-1}$ at room temperature. Three identical tensile tests were performed to evaluate tensile properties. After tensile tests, the fracture surfaces were cut from the fracture surfaces and examined by SEM. 


\section{Results and Discussion.}

2.1. Microstructure Characteristics. The OM observation results on casting $\mathrm{Mg}-\mathrm{Y}-\mathrm{Nd}-\mathrm{Zr}$ alloy are depicted in Fig. 1. Obviously, the casting alloy mainly comprises the $\alpha-\mathrm{Mg}$ matrix and strengthening phase along the grain boundary, as shown in Fig. 1a. The $\alpha-\mathrm{Mg}$ matrix is almost separated by the discontinuously strengthening phase and exhibits the cell structure. The statistical analysis on the casting $\mathrm{Mg}-\mathrm{Y}-\mathrm{Nd}-\mathrm{Zr}$ alloy indicates that its average grain size is about $70 \mu \mathrm{m}$. The strengthening phase can be divided into two kinds. The first one has a small size and is distributed semi-continuously along the grain boundary, while the second one has a large size and forms the eutectic structure with the $\alpha-\mathrm{Mg}$ matrix, as shown in Fig. $1 \mathrm{~b}$.
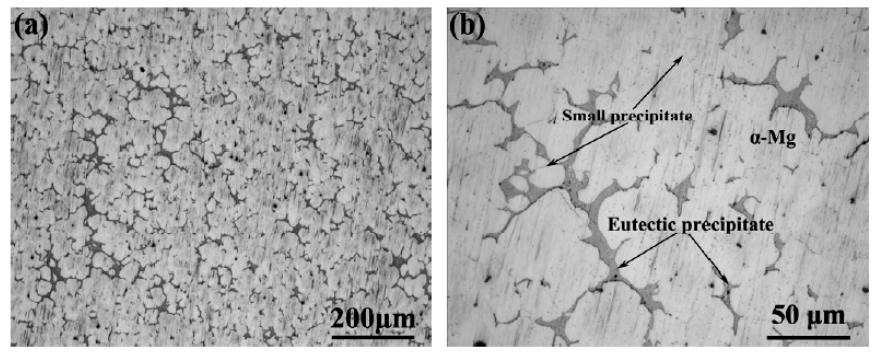

Fig. 1. OM image of the casting $\mathrm{Mg}-\mathrm{Y}-\mathrm{Nd}-\mathrm{Zr}$ alloy: (a) microstructure of the casting alloy; (b) morphology of the strengthening phase.

SEM observations on the casting $\mathrm{Mg}-\mathrm{Y}-\mathrm{Nd}-\mathrm{Zr}$ alloy are shown in Fig. 2. The back-scattered SEM image shows that the black $\alpha$-Mg phase is surrounded by white strengthening phases, as shown in Fig. 2a. Moreover, the $\mathrm{Y}, \mathrm{Nd}$, and $\mathrm{Zr}$ elements are segregated along the grain boundary, which is seen as a gray region adjacent to the grain boundary. In addition, a white strengthening phase exhibits an obvious segregation and some regions are covered by the bulk strengthening phase with an eutectic structure. Further observation of the grain boundary shows that there are small white precipitates, as seen in Fig. 2b. The bulk strengthening phase and small precipitate separate the matrix into cell structures. The EDS analysis on the bulk strengthening phase shows that it is rich of $\mathrm{Nd}$ and contains some $\mathrm{Y}$, as shown in Fig. 2c.
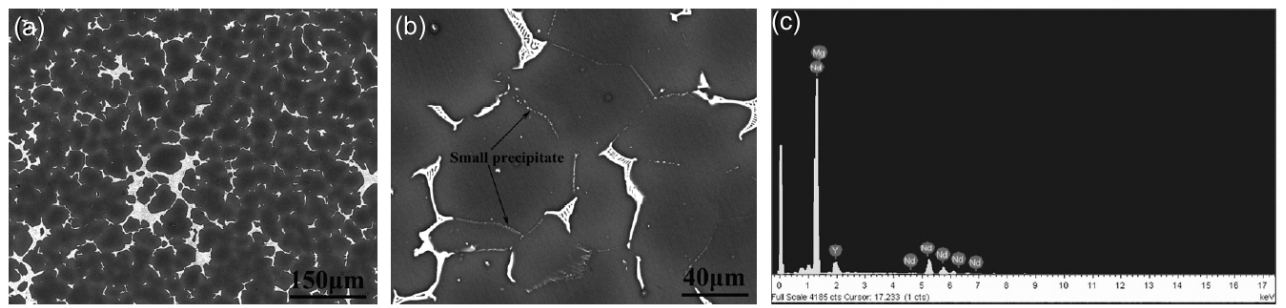

Fig. 2. Back-scattered SEM image of the casting alloy: (a) microstructure of the strengthening phase; (b) distribution of small precipitates along grain boundary; (c) EDS analysis of the bulk precipitate.

To identify the constituent phases in the casting $\mathrm{Mg}-\mathrm{Y}-\mathrm{Nd}-\mathrm{Zr}$ alloy, the XRD analysis is carried out. Figure 3 exhibits the XRD pattern of the casting $\mathrm{Mg}-\mathrm{Y}-\mathrm{Nd}-\mathrm{Zr}$ alloy, which indicates that the casting alloy is mainly comprised of $\alpha-\mathrm{Mg}, \mathrm{Mg}_{12} \mathrm{Nd}$, and $\mathrm{Mg}_{24} \mathrm{Y}_{5}$ phases. Based on the peak intensity, one can deduce that the share of $\mathrm{Mg}_{24} \mathrm{Y}_{5}$ is higher than that of the $\mathrm{Mg}_{12} \mathrm{Nd}$ phase. In addition, the $\alpha$-Mg matrix exhibits a strong crystal growth preference along (101). 


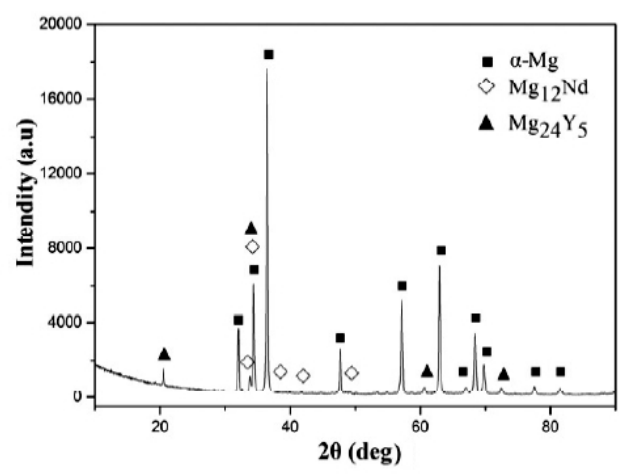

Fig. 3. XRD pattern of the casting $\mathrm{Mg}-\mathrm{Y}-\mathrm{Nd}-\mathrm{Zr}$ alloy.
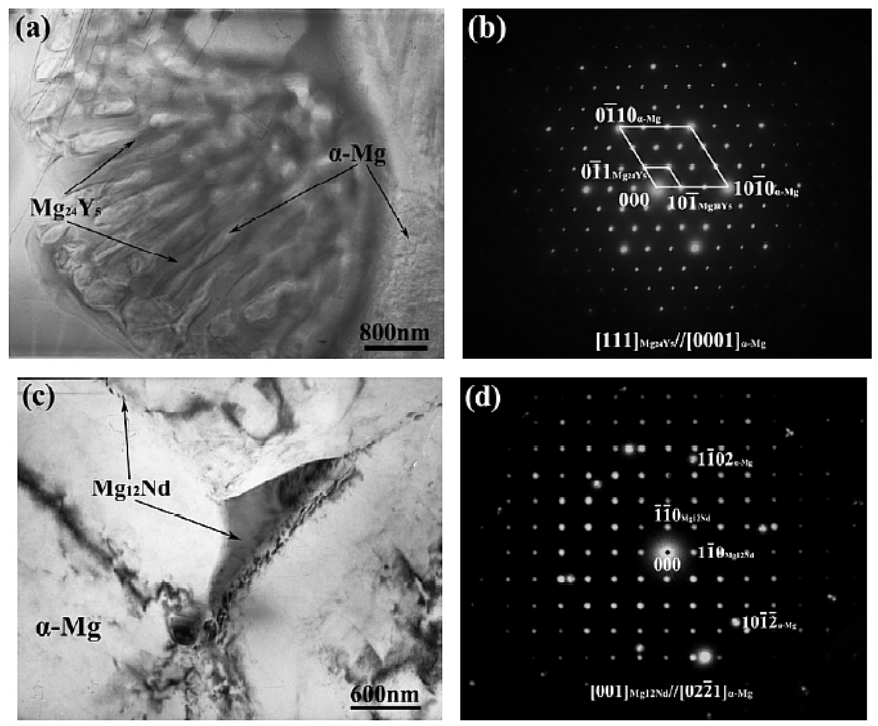

Fig. 4. TEM image of precipitates in the casting $\mathrm{Mg}-\mathrm{Y}-\mathrm{Nd}-\mathrm{Zr}$ alloy: (a) morphology of the $\mathrm{Mg}_{24} \mathrm{Y}_{5} /$ $\alpha-\mathrm{Mg}$ eutectic structure; (b) SAED pattern of the $\mathrm{Mg}_{24} \mathrm{Y}_{5} / \alpha-\mathrm{Mg}$ eutectic structure; (c) morphology of the $\mathrm{Mg}_{12} \mathrm{Nd}$ phase along the grain boundary; (d) SAED pattern of the $\mathrm{Mg}_{12} \mathrm{Nd}$ phase.

To confirm the precipitates further, the TEM observation has been carried out and the results are depicted in Fig. 4. It can be found that there are fine eutectic structure in the casting alloy, as shown in Fig. 4a. The selected area electron diffraction (SAED) pattern of the fine eutectic structure exhibits that the phases in the eutectic structure are $\alpha-\mathrm{Mg}$ and $\mathrm{Mg}_{24} \mathrm{Y}_{5}$ phases, as shown in Fig. $4 \mathrm{~b}$. The $\mathrm{Mg}_{24} \mathrm{Y}_{5}$ phase possesses the body-centered crystal lattice $(a=b=c=1.120 \mathrm{~nm})$ with $\mathrm{I} 4 / \mathrm{mmm}$ space group. In the eutectic structure, the $\alpha$-Mg and $\mathrm{Mg}_{24} \mathrm{Y}_{5}$ phase lamellas are aligned alternately forming the chrysanthemum-like shape. The average thickness of $\alpha$-Mg lamella is about $300 \mathrm{~nm}$ and that of $\mathrm{Mg}_{24} \mathrm{Y}_{5}$ lamella is about $250 \mathrm{~nm}$. Moreover, the SAED pattern also demonstrates that the $\mathrm{Mg}_{24} \mathrm{Y}_{5}$ phase and $\alpha-\mathrm{Mg}$ matrix have orientation relationships of $[111]_{\mathrm{Mg}_{24} \mathrm{Y}_{5}} / /[0001]_{\alpha-\mathrm{Mg}}$ and $(101)_{\mathrm{Mg}_{24} \mathrm{Y}_{5}} / /(1010)_{\alpha-\mathrm{Mg}}$. Though the well matched phase interface is beneficial to improve the cohesion between phases, the eutectic structure of the strengthening phase might be detrimental to the mechanical properties by promotion of stress concentration along the eutectic boundary [20]. Further observation on the grain boundary region shows that there are precipitates with dual-size, as shown in Fig. 4c. The SAED pattern reveals 
that the phase is $\mathrm{Mg}_{12} \mathrm{Nd}$, which has a tetragonal crystal lattice $(a=b=1.031 \mathrm{~nm}$ and $c=0.593 \mathrm{~nm}$ ) with the I4/mmm space group, as shown in Fig. 4d. Moreover, the SAED pattern also demonstrates that the $\mathrm{Mg}_{12} \mathrm{Nd}$ phase and $\alpha-\mathrm{Mg}$ matrix have the orientation of $[001]_{\mathrm{Mg}_{12} \mathrm{Nd}} / /[02 \overline{2} 1]_{\alpha-\mathrm{Mg}}$. Combined with the SEM observation, large $\mathrm{Mg}_{12} \mathrm{Nd}$ phase has the size of $2-3 \mu \mathrm{m}$, while a small one has the size of $80-150 \mathrm{~nm}$. The morphology and distribution of $\mathrm{Mg}_{12} \mathrm{Nd}$ phase can be instrumental for mechanical properties by impeding the dislocation motion.

The hot extrusion results in great microstructure evolution of the alloy, as exhibited in Fig. 5. No eutectic structure and bulk precipitate exist in the extruded alloy. The original strengthening phases have been fragmented into small ones and exhibited rheological morphology, as exhibited in Fig. 5a. Moreover, the fragmented strengthening phases align discontinuously and are parallel with the extrusion direction. The distance between the aligned strengthening phases varies from several to tens of microns, which may be attributed to the inhomogeneous distribution of original strengthening phase, especially the bulk $\alpha-\mathrm{Mg} / \mathrm{Mg}_{24} \mathrm{Y}_{5}$ eutectic structure. According to recent researches [21, 22], the presence of stiffness particle benefits the grain refinement by segmenting the original grain during the extrusion. However, in the present research, the coarse eutectic structure and Mg matrix have to deform synergistically during the extrusion, which results in the simultaneous fragmentation. As seen in Fig. 5b, the fragmented particles exhibit irregular shape and aggregation morphology. Moreover, ultrafine precipitates along the grain boundary (GB) can be observed. Based on the SEM observation, it can be concluded that the hot-extruded alloy has the average grain size of about $13 \mu \mathrm{m}$.
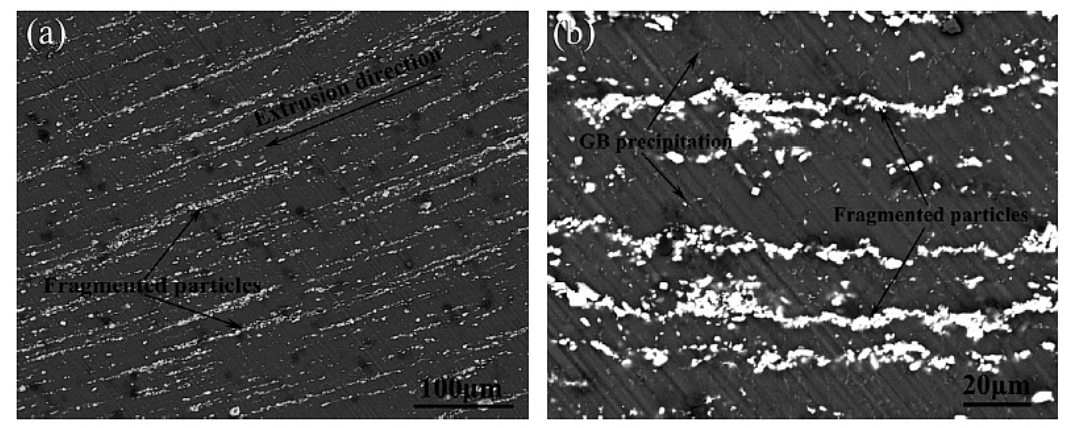

Fig. 5. Back-scattered SEM image of the hot extruded alloy: (a) fragmented strengthening phase and its regular distribution in the hot extruded alloy; (b) morphology of small particle distributed along grain boundary.

The XRD analysis results on the hot-extruded $\mathrm{Mg}-\mathrm{Y}-\mathrm{Nd}-\mathrm{Zr}$ alloy is depicted in Fig. 6. Distinctly, the constituent phases in the hotextruded alloy are mainly $\mathrm{Mg}_{12} \mathrm{Nd}$, $\mathrm{Mg}_{24} \mathrm{Y}_{5}$ and $\alpha-\mathrm{Mg}$ ones. As compared with the casting alloy, the crystal orientation preferences of all phases have almost no changes. The difference is that the intensity of $\alpha$-Mg along (101) sharply decreases, while that along (102) sharply increases. The XRD pattern indicates the hot extrusion exerts a feeble effect on the alloy texture, which may be attributed to the relatively low extrusion temperature.

TEM observation on the hot-extruded alloy proves that the hot extrusion results in a strong microstructural evolution, as seen in Fig. 7. Along the refined grain boundary, the GB precipitates almost connect with each other and form the cell wall of the $\alpha$-Mg grain, as shown in Fig. 7a. Moreover, small fragmented particles traverse the $\alpha$-Mg grain. Further observation on the deformed matrix reveals that a large deformation leads to some strip structure, as shown in Fig. 7b. The inset SAED pattern reveals that the diffraction spots tend to be connected by a line, which indicates that stacking faults are formed in the strip 


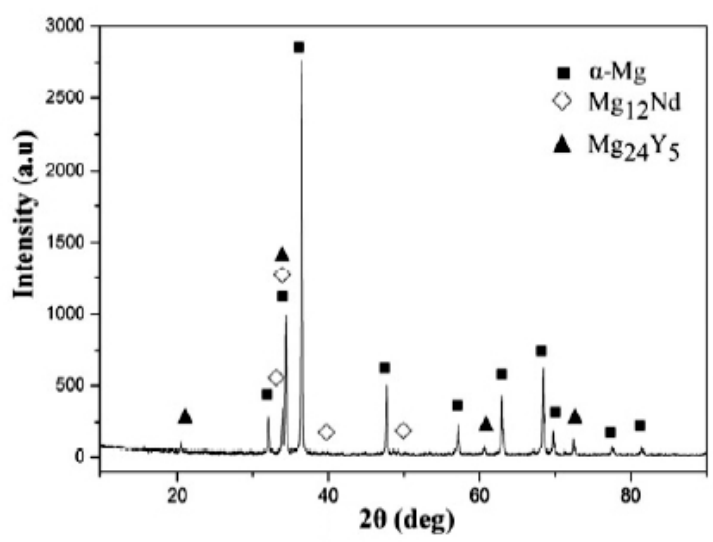

Fig. 6. XRD pattern of the hot-extruded $\mathrm{Mg}-\mathrm{Y}-\mathrm{Nd}-\mathrm{Zr}$ alloy.
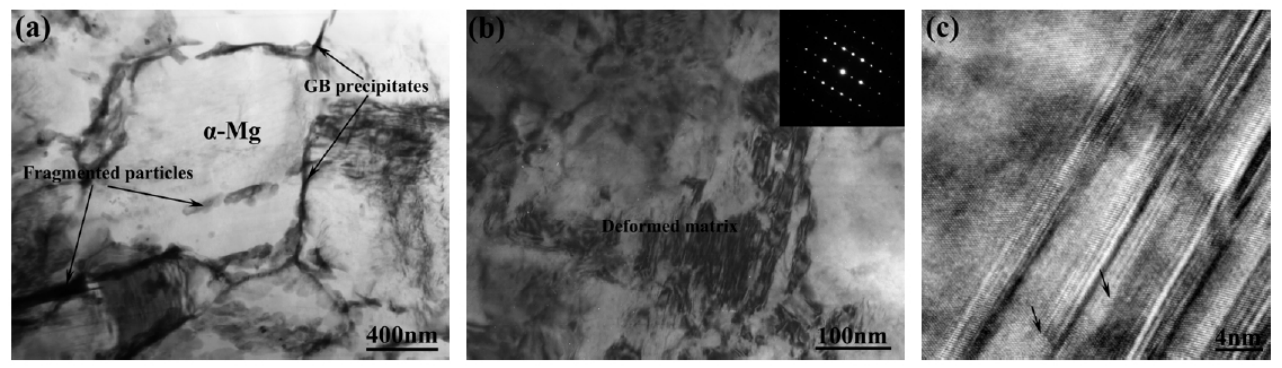

Fig. 7. TEM observation on precipitates and deformed matrix in the hot-extruded $\mathrm{Mg}-\mathrm{Y}-\mathrm{Nd}-\mathrm{Zr}$ alloy: (a) morphology of fragmented particles and precipitates along the grain boundary; (b) morphology of the severely deformed matrix (inset image showing the SAED pattern); (c) HRTEM image of the severely deformed matrix showing stacking faults.

structure. The high-resolution TEM observation on the strip structure confirms the SAED analysis results, as seen in Fig. 7c. There is obvious atom misplacement between the crystal plane and its width is $2-5 \mathrm{~nm}$. Moreover, stacking faults are initiated from the grain interior as indicated by the arrow. Based on the former research [23-27], a large deformation during the hot extrusion would lead to large stresses and crystal torsion, which facilitate the formation of crystal defects.

2.2. Mechanical Properties. To evaluate the effect of hot extrusion on mechanical properties of the $\mathrm{Mg}-\mathrm{Zn}-\mathrm{Y}-\mathrm{Nd}$ alloy, the tensile tests of the casting and hot-extruded alloys were carried out. The tensile curves and mechanical properties of the casting and hot-extruded alloys are shown in Fig. 8. Hot-extruded and casting alloys demonstrate a similar deformation behavior comprising of yield state and plastic deformation stage, as shown in Fig. 8a. The main difference between them is that the hot-extruded alloy has higher strength and longer deformation stage. The analysis of mechanical properties reveals that the hot extrusion has improved the elongation, ultimate tensile strength (UTS), and yield strength (YS), as shown in Fig. 8b. The ultimate tensile and yield strength values of hot-extruded alloy are almost twice and by $50 \%$ higher, respectively, than those of the casting alloy. In addition, the YS/UTS ratios of casting and hot-extruded alloys are equal to 0.8 and 0.6. According to the recent research [26], the YS/UTS ratio reduction is beneficial to the alloy safety during the deformation, because the resulting alloy would possess more deforming tolerance. In addition, the hot extrusion increases the elongation of alloy to $15 \%$, which value is more than twice higher than that of the casting alloy. 


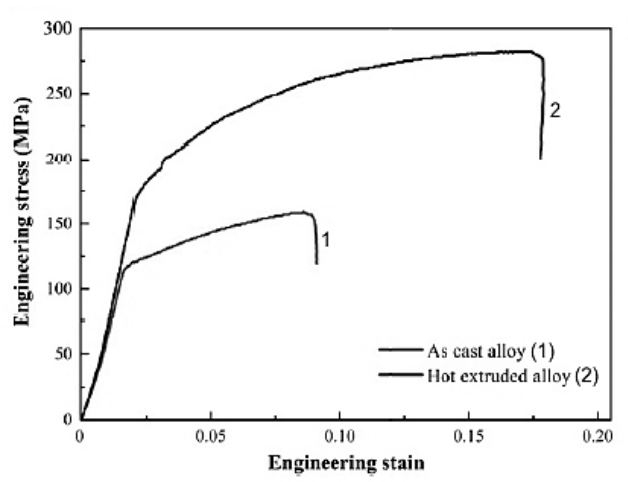

a

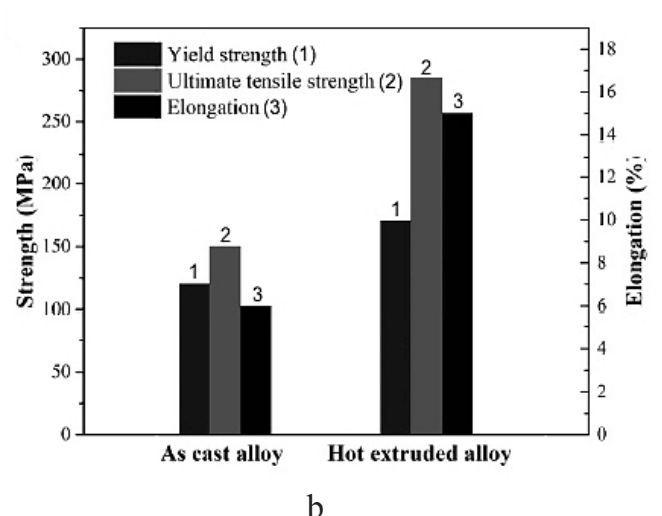

b

Fig. 8. Tensile curves (a) and mechanical properties (b) of casting and hot-extruded $\mathrm{Mg}-\mathrm{Y}-\mathrm{Nd}-\mathrm{Zr}$ alloys.

Observations on fracture surfaces of casting and hot-extruded $\mathrm{Mg}-\mathrm{Y}-\mathrm{Nd}-\mathrm{Zr}$ alloys after tensile test are shown in Fig. 9 and exhibit the difference in the fracture modes. For the casting alloy, its fracture surface exhibits typical brittle fractography which comprises transgranular cleavage and intergranular debonding, as shown in Fig. 9a. The morphology of small grains still can be observed on the fracture surface as indicated by the arrow. Moreover, there are some dimples in the fracture surface. Based on the microstructure observation of casting alloy, the coarse eutectic structure and fine GB precipitates along the grain boundary are mainly responsible for the fracture mode. Due to the high stiffness of the $\mathrm{Mg}_{12} \mathrm{Nd}$ and $\mathrm{Mg}_{24} \mathrm{Y}_{5}$ phases, the dislocations would accumulate along these phase interfaces, promoting the stress concentration [26]. A larger size of stiff phase would result in a higher stress concentration, so the coarse $\mathrm{Mg}_{24} \mathrm{Y}_{5} / \alpha-\mathrm{Mg}$ eutectic structure becomes the main crack initiation source. Moreover the brittleness of $\mathrm{Mg}_{24} \mathrm{Y}_{5}$ phase accelerates the crack propagation speed and implies the cleavage fracture pattern. A small $\mathrm{Mg}_{12} \mathrm{Nd}$ phase could act as the obstacle of mobile dislocation and the initiation of the dimples. In contrast to casting alloys, the fracture surface of hot-extruded alloys exhibits more ductile feature, as shown in Fig. 9b. Moreover, the size of cleavage becomes small and number of dimples increase obviously, which should be ascribed to the grain refinement and fragment of coarse eutectic structure.
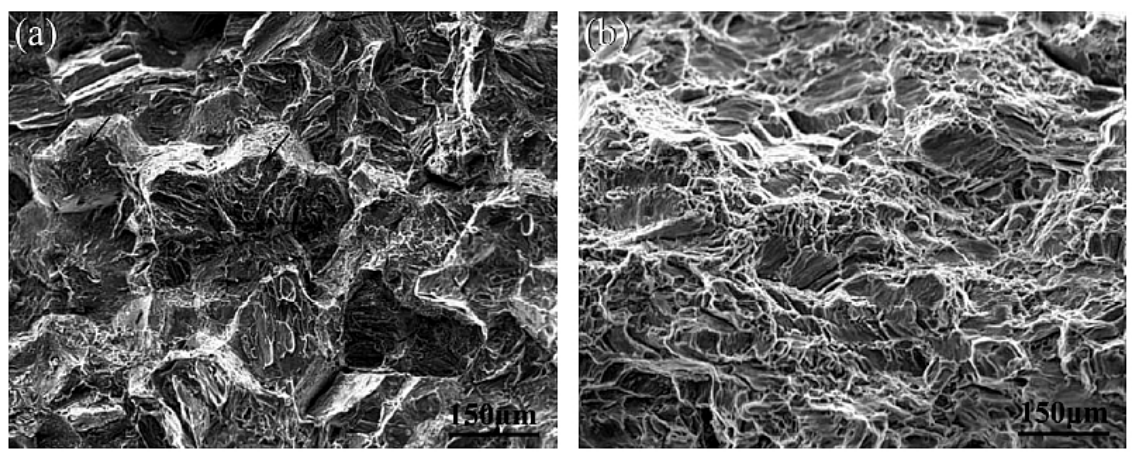

Fig. 9. Fracture surface of the tensile test specimen: (a) casting alloy, (b) hot-extruded alloy.

According to the recent studies [27, 28], the microstructural evolution is controlled by processing parameters and the original strengthening phase morphology. The high extrusion ratio and low extrusion temperature would generate ultrafine grains and massive 
substructures. Coarse and segregated original strengthening phases improve the deformation resistance and are detrimental to the grain refinement. Small and uniformly distributed original strengthening phases are beneficial to the synergetic deformation and grain refinement. In the present study, about $7.4 \%$ of $\mathrm{Y}$ and $\mathrm{Nd}$ is added in the $\mathrm{Mg}$ alloy, which exceeds the solid solubility of $\mathrm{Nd}$ and $\mathrm{Y}$ in $\mathrm{Mg}$. Therefore, the superfluous $\mathrm{Y}$ and $\mathrm{Nd}$ would react with $\mathrm{Mg}$ and form the precipitates. Due to relatively high eutectic temperature of $\mathrm{Mg}-\mathrm{Y}$ and sufficient supply of $\mathrm{Y}$, the $\mathrm{Mg}_{24} \mathrm{Y}_{5}$ phase precipitates grow into the bulk eutectic structure. The $\mathrm{Nd}$ element mainly precipitates in the form of relatively small $\mathrm{Mg}_{12} \mathrm{Nd}$ particles along the grain boundary. The coarse eutectic structure is harmful to the ductility, due to its obvious stress concentration effect. During the extrusion of the mold neck, a high torsion promotes the refinement of the $\alpha-\mathrm{Mg}$ matrix and fragmentation of the $\mathrm{Mg}_{24} \mathrm{Y}_{5} / \alpha-\mathrm{Mg}$ eutectic structure. Moreover, the joint effect of fragmented strengthening particles and extrusion contributes to the grain refinement. Additionally, a large deformation in $\alpha$-Mg matrix results in the formation of crystal defects, such as dislocations, stacking fault and microtwinning [7, 29]. Based on recent findings [25, 30-32], original crystal defects would impede the motion of dislocations and enhance the strength. Furthermore, the refined $\alpha-\mathrm{Mg}$ matrix and strengthening particles increase the ductility and strength of the hot-extruded alloy. Although the refined microstructure is beneficial to the mechanical properties, the aligned strengthening phase along the extrusion direction deteriorates the synergetic deformability, which offsets the improvement of mechanical propertiesy. Therefore, it can be concluded that the improved mechanical properties of the $\mathrm{Mg}-\mathrm{Y}-\mathrm{Nd}-\mathrm{Zr}$ alloy should be ascribed to microstructure optimization of grain size, distribution of strengthening phase, and substructure by the hot extrusion.

Conclusions. In this study, the $\mathrm{Mg}-\mathrm{Y}-\mathrm{Nd}-\mathrm{Zr}$ alloy was prepared by the conventional casting and subsequent hot extrusion. Different fabrication methods significantly change the microstructure and mechanical properties. In the casting $\mathrm{Mg}-\mathrm{Y}-\mathrm{Nd}-\mathrm{Zr}$ alloy, the $\alpha-\mathrm{Mg}$ matrix is separated into cell structures by discontinuously distributed $\mathrm{Mg}_{24} \mathrm{Y}_{5} / \alpha-\mathrm{Mg}$ eutectic structures and $\mathrm{Mg}_{12} \mathrm{Nd}$ particles. The $\mathrm{Mg}_{12} \mathrm{Nd}$ and $\mathrm{Mg}_{24} \mathrm{Y}_{5}$ phases have the following orientation with the $\alpha-\mathrm{Mg}$ matrix: $[001]_{\mathrm{Mg}_{12} \mathrm{Nd}} / /[0221]_{\alpha-\mathrm{Mg}},[111]_{\mathrm{Mg}_{24} \mathrm{Y}_{5}} / /$ $[0001]_{\alpha-\mathrm{Mg}}$, and $(10 \overline{1})_{\mathrm{Mg}_{24} \mathrm{Y}_{5}} / /(1010)_{\alpha-\mathrm{Mg}}$. The hot extrusion fragments the $\mathrm{Mg}_{24} \mathrm{Y}_{5} / \alpha-\mathrm{Mg}$ eutectic structure and aligns fragmented $\mathrm{Mg}_{24} \mathrm{Y}_{5}$ particles along the extrusion direction. The joint effect of hot extrusion and strengthening particles refines the $\alpha-\mathrm{Mg}$ fraction. Moreover, large deformation results in the stacking faults in the matrix. As compared with the casting $\mathrm{Mg}-\mathrm{Y}-\mathrm{Nd}-\mathrm{Zr}$ alloy, the hot extrusion improves the elongation, ultimate tensile strength, and yield strength, which should be ascribed to the optimized distribution of strengthening particles, grain refinement, and massive substructures.

Acknowledgments. The authors are grateful to the Shenzhen Technology Innovation Plan (CXZZ20140731091722497 and CXZZ20140419114548507) and the Strategic New Industry Development Special Foundation of Shenzhen (JCYJ20150529162228734, JCYJ20160427100211076, JCYJ20170306141749970，JCYJ20160329161539885，JCYJ 20150625155931806 and JCYJ20160427170611414) for the financial support.

1. M. M. Avedesian and H. Baker (Eds.), Magnesium and Magnesium Alloys, ASM International, Materials Park, OH (1999).

2. Z. Liu, Y. Wang, and Z. G. Wang, "The research and application of magnesium matrix of lightweight materials," J. Mater. Res., 14, No. 5, 449-56 (2000).

3. Z. J. Li, X. N. Gu, S. Q. Lou, and Y. F. Zheng, "The development of binary Mg-Ca alloys for use as biodegradable materials within bone," Biomaterials, 29, No. 10, 1329-1344 (2008). 
4. B. L. Mordike and T. Ebert, "Magnesium: properties - applications - potential," Mater. Sci. Eng. A, 302, No. 1, 37-45 (2001).

5. M. Haude, H. Ince, A. Abizaid, et al., "Safety and performance of the secondgeneration drug-eluting absorbable metal scaffold in patients with de-novo coronary artery lesions (BIOSOLVE-II): 6 month results of a prospective, multicentre, nonrandomised, first-in-man trial," Lancet, 387, No. 10013, 31-39 (2016).

6. S. B. Yi, C. H. J. Davies, H. G. Brokmeier, et al., "Deformation and texture evolution in AZ31 magnesium alloy during uniaxial loading," Acta Mater., 54, No. 2, 549-562 (2006).

7. C. Q. Li, D. K. Xu, B. J. Wang, et al., "Natural ageing responses of duplex structured Mg-Li based alloys," Sci. Rep., 7, 40078 (2017).

8. J. A. del Valle, F. Carreno, and O. A. Ruano, "Influence of texture and grain size on work hardening and ductility in magnesium-based alloys processed by ECAP and rolling," Acta Mater., 54, No. 16, 4247-4259 (2006).

9. B. Feng, Y. C. Xin, F. L. Guo, et al., "Compressive mechanical behavior of Al/Mg composite rods with different types of Al sleeve," Acta Mater., 120, 379-390 (2016).

10. Y. M. Zhu, A. J. Morton, and J. F. Nie, "The $18 \mathrm{R}$ and $14 \mathrm{H}$ long-period stacking ordered structures in Mg-Y-Zn alloys," Acta Mater., 58, No. 8, 2936-2947 (2010).

11. L. Gao, R. S. Chen, and E. H. Han, "Effects of rare-earth elements Gd and Y on the solid solution strengthening of Mg alloys," J. Alloy. Compd., 481, Nos. 1-2, 379-384 (2009).

12. S. Sandloebes, M. Friak, S. Zaefferer, et al., "The relation between ductility and stacking fault energies in $\mathrm{Mg}$ and $\mathrm{Mg}-\mathrm{Y}$ alloys," Acta Mater., 60, Nos. 6-7, 30113021 (2012).

13. J. Cheng, Y. L. Mu, G. Y. Zu, and G. C. Yao, "Impact toughness and fractography in Mg-Y alloy," Mater. Design, 123, 64-68 (2017).

14. A. Kula, X. Jia, R. K. Mishra, and M. Niewczas, "Flow stress and work hardening of Mg-Y alloys," Int. J. Plasticity, 92, 96-121 (2017).

15. C. Q. Li, D. K. Xu, Z. R. Zeng, et al., "Effect of volume fraction of LPSO phases on corrosion and mechanical properties of $\mathrm{Mg}-\mathrm{Zn}-\mathrm{Y}$ alloys," Mater. Design, 121, 430-441 (2017).

16. H. Z Li, F. Lv, X. P. Liang, et al., "Effect of heat treatment on microstructures and mechanical properties of a cast $\mathrm{Mg}-\mathrm{Y}-\mathrm{Nd}-\mathrm{Zr}$ alloy," Mater. Sci. Eng. A, 667, 409-416 (2016).

17. Z. Xu, M. Weylandm, and J. F. Nie, "On the strain accommodation of $\beta_{1}$ precipitates in magnesium alloy WE54," Acta Mater., 75, 122-133 (2014).

18. S. Zhao, E. Guo, G. Cao, et al., "Microstructure and mechanical properties of $\mathrm{Mg}-\mathrm{Nd}-\mathrm{Zn}-\mathrm{Zr}$ alloy processed by integrated extrusion and equal channel angular pressing," J. Alloy. Compd., 705, 118-125 (2017).

19. X. Liu, R. Chen, and E. Han, "High temperature deformations of Mg-Y-Nd alloys fabricated by different routes," Mater. Sci. Eng. A, 497, 326-332 (2008).

20. L. Y. Sheng, F. Yang, J. T. Guo, and T. F. Xi, "Anomalous yield and intermediate temperature brittleness behaviors of directionally solidified nickel-based superalloy," Trans. Nonferr. Metal. Soc. China, 24, 673-681 (2014).

21. L. Y. Sheng, F. Yang, T. F. Xi, et al., "Microstructure evolution and mechanical properties of $\mathrm{Ni} 3 \mathrm{Al} / \mathrm{Al}_{2} \mathrm{O}_{3}$ composite during self-propagation high-temperature synthesis and hot extrusion," Mater. Sci. Eng. A, 555, 131-138 (2012). 
22. L. Y. Sheng, T. F. Xi, C. Lai, et al., "Effect of extrusion process on microstructure and mechanical properties of $\mathrm{Ni}_{3} \mathrm{Al}-\mathrm{B}-\mathrm{Cr}$ alloy during self-propagation high-temperature synthesis," Trans. Nonferr. Metal. Soc. China, 22, No. 3, 489-495 (2012).

23. L. Y. Sheng, F. Yang, T. F. Xi, et al., "Influence of heat treatment on interface of $\mathrm{Cu} / \mathrm{Al}$ bimetal composite fabricated by cold rolling," Compos. Part B - Eng., 42, 1468-1473 (2011).

24. L. Y. Sheng, J. T. Guo, T. F. Xi, et al., " $\mathrm{ZrO}_{2}$ strengthened $\mathrm{NiAl} / \mathrm{Cr}(\mathrm{Mo}, \mathrm{Hf})$ composite fabricated by powder metallurgy," Prog. Nat. Sci. - Mater., 22, No. 3, 231-236 (2012).

25. L. Y. Sheng, F. Yang, T. F. Xi, et al., "Improvement of compressive strength and ductility in $\mathrm{NiAl}-\mathrm{Cr}(\mathrm{Nb}) / \mathrm{Dy}$ alloy by rapid solidification and HIP treatment," Intermetallics, 27, 14-20 (2012).

26. C. Q. Li, D. K. Xu, S. Yu, et 1., "Effect of icosahedral phase on crystallographic texture and mechanical anisotropy of Mg-4\%Li based alloys," J. Mater. Sci. Technol., 33, No. 5, 475-480 (2017).

27. L. Y. Sheng, F. Yang, J. T. Guo, et al., "Investigation on NiAl-TiC- $\mathrm{Al}_{2} \mathrm{O}_{3}$ composite prepared by self-propagation high temperature synthesis with hot extrusion," Compos. Part B - Eng., 45, No. 1, 785-791 (2013).

28. L. Y. Sheng, W. Zhang, J. T. Guo, et al., "Microstructure and mechanical properties of $\mathrm{Ni}_{3} \mathrm{Al}$ fabricated by thermal explosion and hot extrusion," Intermetallics, 17, No. 7, 572-577 (2009)

29. L. Y. Sheng, J. T. Guo, W. L. Ren, et al., "Preliminary investigation on strong magnetic field treated NiAl-Cr(Mo)-Hf near eutectic alloy," Intermetallics, 19, No. 2, 143-148 (2011).

30. L. Y. Sheng, B. N. Du, C. Lai, et al., "Influence of tantalum addition on microstructure and mechanical properties of the NiAl-based eutectic alloy," Strength Mater., 49, No. 1, 109-117 (2017).

31. L. Y. Sheng, "Microstructure and wear properties of the quasi-rapidly solidified NiAl/Cr(Mo,Dy) hypoeutectic alloy," Strength Mater., 48, No. 1, 107-112 (2016).

32. L. Y. Sheng, J. T. Guo, and H. Q. Ye, "Microstructure and mechanical properties of $\mathrm{NiAl}-\mathrm{Cr}(\mathrm{Mo}) / \mathrm{Nb}$ eutectic alloy prepared by injection-casting," Mater. Design, 30, No. 4, 964-969 (2009). 